Većeslav Čorić

Smiljko Rudan

Slobodan Maksimović

http://dx.doi.org/10.21278/brod68406

ISSN 0007-215X

eISSN 1845-5859

\title{
TECHNOLOGY OF SUBSEA PIPELINE LAYING IN THE COASTAL AREA
}

UDC 624.157:519.6

Professional paper

\begin{abstract}
Summary
The paper describes technology applied in laying the subsea crude oil pipeline in the coastal area of the northern Adriatic, between the steep coasts of island Krk and mainland. Very detailed functional plan was produced in order to avoid possible critical and unexpected situations in the installation process. The most critical actions of the process were numerically modelled and analysed in realistic numerical simulation to verify the defined project functional plan. The numerical model has taken into consideration large displacement mechanic and contact problem of elastic body in collision with rigid sea bottom. On the basis of the proofed functional plan a precise organization of the process was defined with a focus on the synchronization of all depending actions.
\end{abstract}

Key words: $\quad$ subsea pipeline laying; control bending; large displacement-small deformation; contact problem; finite element method;

\section{Introduction}

A relatively short subsea pipeline segment, connecting island Krk and land coasts, was laid to replace the existing JANAF crude oil pipeline segment passing over the near bridge. In spite of the short pipeline segment length and a shallow sea, the project of pipeline laying was faced with many challenging details. The main reason for that was relatively stiff composite pipe section (concrete coated NP 36" pipe, see Table 1). The other reasons were a steep ground on the pipeline lowering points both on the island and land coasts as well as unevenly curved sea bottom. In addition, no special pipeline laying barge could be engaged in the limited sea area between the island and the land so one suitable and appropriate technology had to be defined and applied. The laying was accomplished with standard pontoons equipped by either excavators or mobile cranes. To avoid any possible accident during the laying process, consisting of many critical steps, an excessive engineering was made to define reliable technology and organization. The result of these engineering works was the top analysis of the dynamics of the laying process and good and detailed functional and operational plans.

Three equal pipeline sections were manufactured by string pipe welding on the prepared working platform on the island. When all three pipeline sections were equipped with primary 
and secondary buoyance elements, they were launched in the sea and assembled into one integrated pipeline segment. The front and aft tags were applied for towing and manoeuvring the composition from the assembling place to the final position, Fig. 1.

Table 1 Subsea pipeline characteristics

\begin{tabular}{|l|r|r|}
\hline Pipe capacity, design & 1,333 & $\mathrm{~m}^{3} / \mathrm{s}$ \\
\hline Pipe diameter (NP 36"), $D$ & 0,914 & $\mathrm{~m}$ \\
\hline Inner diameter & 0,8759 & $\mathrm{~m}$ \\
\hline Material grade & API 5LPSL2: X52M \\
\hline Inner section area & 0,602 & $\mathrm{~m}^{2}$ \\
\hline Modulus of elasticity, $E$ & $2,1 \mathrm{E}+05$ & $\mathrm{MPa}$ \\
\hline Yield strength, $\sigma_{y}$ & 359 & $\mathrm{MPa}$ \\
\hline Fluid density, $\rho$ & 0,850 & $\mathrm{t} / \mathrm{m}^{3}$ \\
\hline Fluid distributed weight, mg & 5,028 & $\mathrm{kN} / \mathrm{m}$ \\
\hline Pipe effective bending stiff., $(E I)$ & $1.215 .850,0$ & $\mathrm{kNm}$ \\
\hline Inner pressure, design, $p_{0}$ & 73,9 & $\mathrm{barg}$ \\
\hline Inner pressure, accident $p_{a}$ & 82,1 & $\mathrm{barg}$ \\
\hline Impulse function (average value): & & $\mathrm{kN}$ \\
\hline Design, $I_{0}$ & $4,454 \mathrm{E}+3$ & $\mathrm{kN}$ \\
\hline Accident, $I_{a}$ & $4,947 \mathrm{E}+03$ & \\
\hline
\end{tabular}

Steep coast on both sides of the pipeline route and applied complex welding technology, excluded the possibility of welding the pipe in floating position and therefore pipeline segment was prefabricated in a total developed length. Due to that, total pipeline segment length was significantly longer then the horizontal distance between the pipeline lowering points, marked LP1 (on the island side) and LP2 (on the land side), see Fig. 2. Therefore, to fit the pipeline segment over the trace line, a precise coordination and synchronization of the construction works was necessary, both during the bending and the positioning the pipeline segment by means of the pontoon cranes and tags.

During all of the installation steps the following criteria had to be fulfilled:

- maximum allowable pipeline uplift displacement,

- adequate safety margin against snap-through buckling,

- minimum acceptable bend radius allowable by the code or specification at installation,

- minimum acceptable ovalisation of the circular pipe section.

Normally, at all time a human safety and safety of the equipment and all objects in the surrounding area had to be realized. Also the impact on the environment had to be avoided.

A favourable weather conditions were required for the following critical parts of the installation procedure:

- the pipeline segment towing,

- the pipeline segment positioning over the trace line,

- lowering the pipeline segment from the sea surface to the sea bottom.

The location of the subsea pipeline route is known for the strong and sudden winds in all seasons causing strong sea current and steep waves. In the main design of subsea pipeline [1], 
the limit sea state during the laying process was defined by significant wave height $h s=0,8 \mathrm{~m}$ and maximum sea current $\mathrm{v}_{\mathrm{C}}=0,5 \mathrm{~m} / \mathrm{s}$. It was decided by criteria of the safe pontoon crane operating in waves. The design wave spectrum was defined from the wind data on the basis of semi-empirical effective fetch relations (SMB methods Sverdrup, Munk, and Bretschneider) and JONSWAP spectrum. The reliable weather forecast at the location could be obtained only for the period of three days ( 72 hours) which defines relative short weather window for critical parts of the installation process.

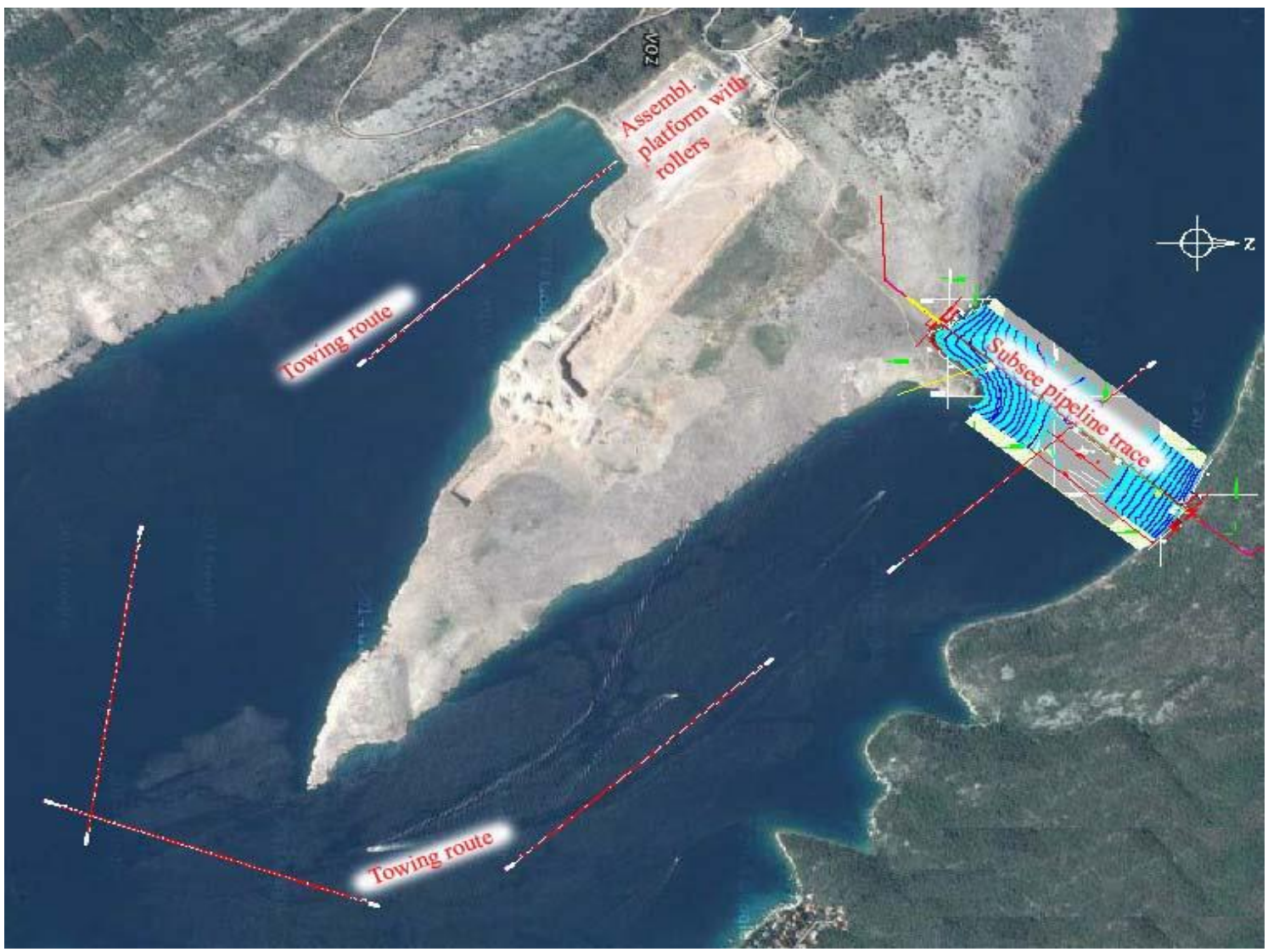

Fig. 1 Assembling platform, towing route and subsea pipeline trace line

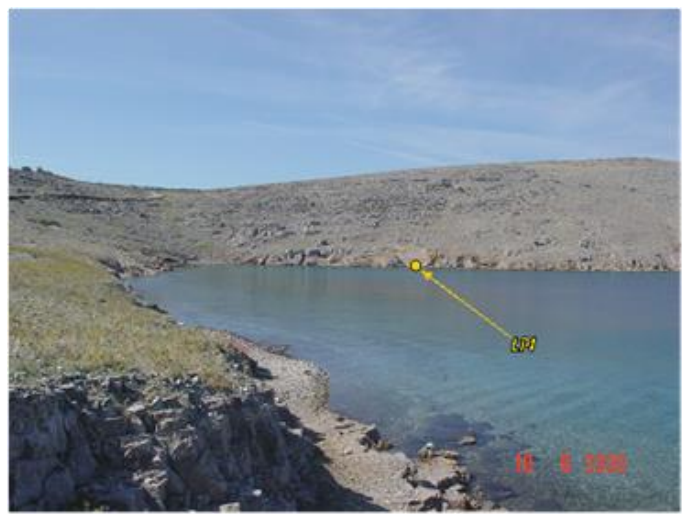

a) Lowering point LP1 on island coast

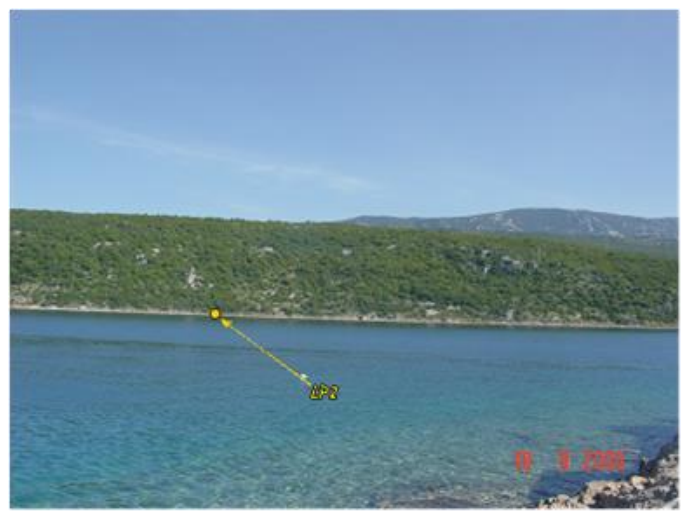

b) Lowering point LP2 on land coast

Fig. 2 Pipeline lowering points LP1, LP2 
Following the golden rule in the offshore industry, the rule which says that nothing unpredicted may happen once the process starts, a comprehensive plan of the installation process was developed describing all the technological and organization details. The conception of the project was based on reliable functional plans described by good text descriptions, verified quantitative design parameters and many graphical description of the process from the top view to the bottom details.

The simulation of the pipeline laying process was based on the commonly accepted standards [2], [3] and code practice [4] which are defined by empirical and semi empirical relations as well as on the detailed numerical analysis which described the pipeline laying as a spatial motion of the flexible structure [1], [5], [6]. The motion of the pipeline from the sea surface to the sea bottom was modelled as a motion of an elastic structure exposed to large displacements at slow velocity and small accelerations. Particular attention was paid to the contact problem between the pipeline and the sea bottom. The nonlinear finite element technique (FEM) and iteration calculations were applied in the analysis. Several variations were analysed to find the optimal one.

\section{Functional plan of the pipe laying process}

The engineering of the pipeline laying process was based on a very detailed functional plan. On the top level, it consists of the following activities, see Fig. 3:

1. production of the pipeline sections on the working platform,

2. welding of the pipeline sections into a complete pipeline segment equipped with the buoyancy elements and launching of it,

3. surface towing of the pipeline segment from the platform to the site,

4. positioning the pipeline segment over the subsea trace line,

5. controlled lowering of the pipeline segment to the sea bottom.

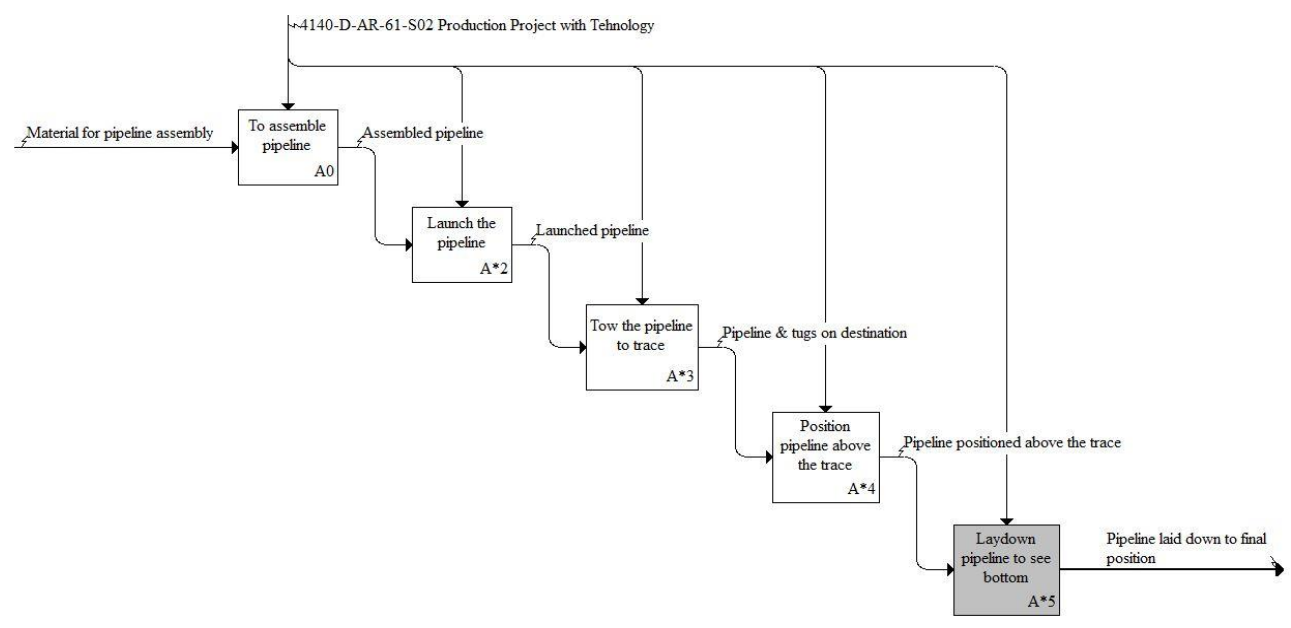

Fig. 3 Functional plan of the pipe laying process, top level

Decomposition of these actions in further details on several levels resulted in a total of 348 logically interconnected activities with clear definition what it means and how it should be realized. A knowledge base technology was used to store all pertaining information in computer system. In order to align numerous activities and links among them, the appropriate software is used. Applied software is based on the input / output methodology [7]. It means that for each activity was defined what needs to be done before the activity begins. What are the mechanisms (equipment, personnel assignments, etc.) that the activity carried out. What are the procedures and the way of control. As output, defined what must be the result of the activity. 


\subsection{Assembling of the pipeline sections on the working platform}

Three pipeline sections were manufactured onshore, on the suitable horizontal working platform. The individual pipes were assembled into pipe strings by adequate method of welding. After the weld inspection and a non-destructive testing were made and sacrificial anodes fixed, the coated pipe joints gaps were filled with a suitable material to produce a continuous pipeline section. The sections were prefabricated along the launching slipway.

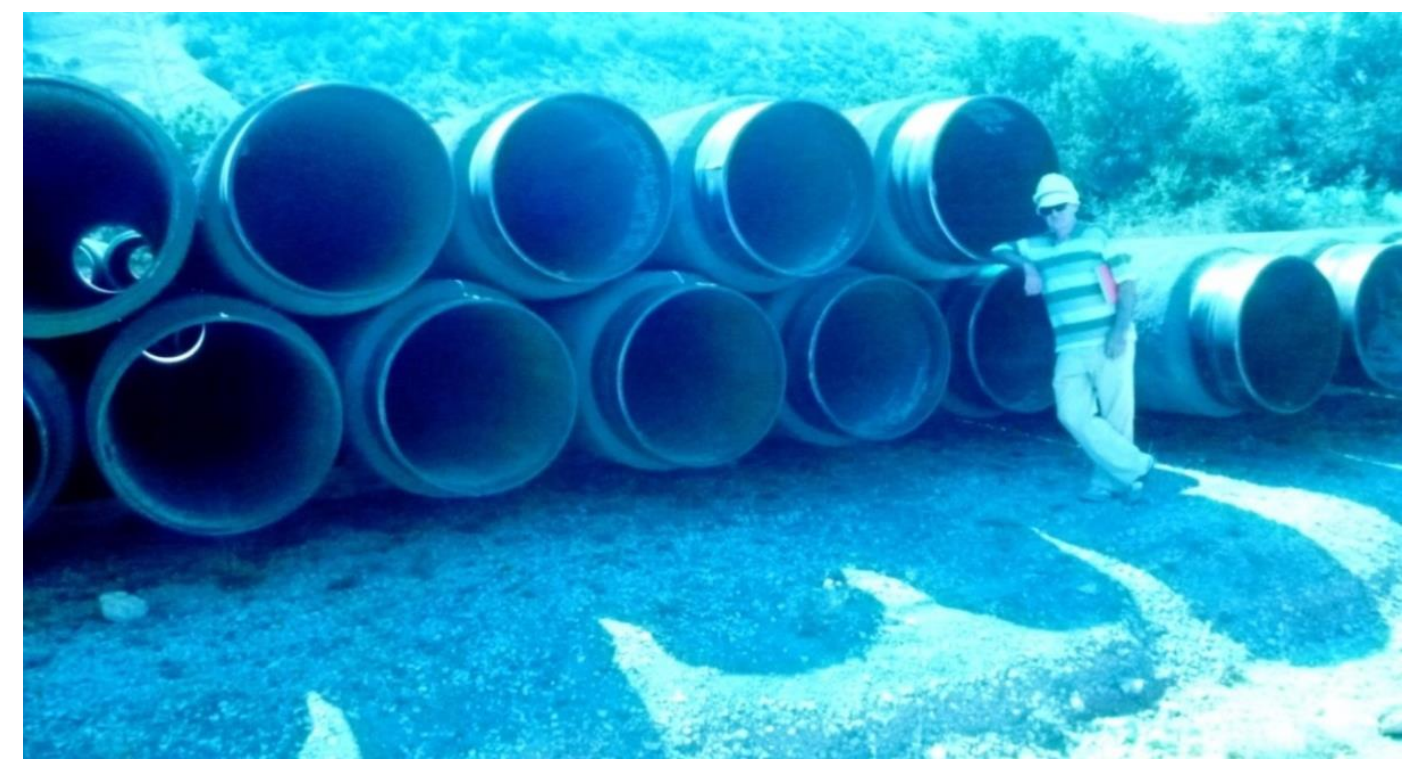

Fig. 4 Subsea pipeline joint elements: concrete coated pipe section NP 36"

\subsection{Launching pipeline sections with buoyant elements}

The pipeline sections were equipped with the primary and secondary buoyant element systems before the launching, see a) and b) in Fig. 4. The effective buoyancy of both systems ensured flotation of the complete pipeline segment in towing on sea surface, from the assembling platform to the location of the pipeline trace line, Fig. 1. The front end and the aft end of the pipeline segment were supplied by the watertight covers fitted with valves for the pressure and a pig test after laying the pipeline segment on the sea bottom.

The secondary buoyant elements were removed after the pipeline segment was positioned and hanged to the pontoons over the pipeline trace line with the island end section laid on the prepared slipway, Fig. 8. Both ends of sections were controlled by two pontoon cranes anchored close to the coasts. The effective buoyancy of the primary system was dimensioned according to the allowable immersed pipe bending moment between the pontoons and according to pontoons winches capacity. 


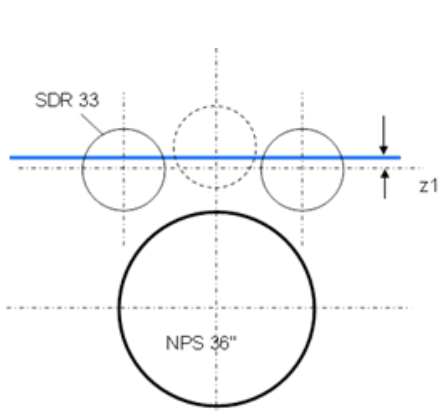

a)

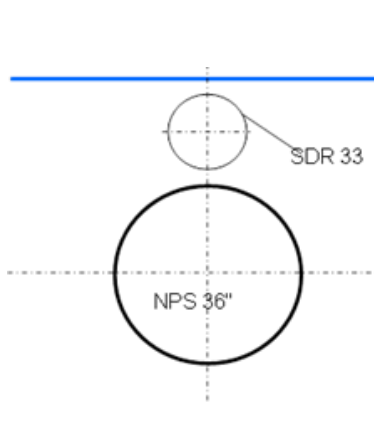

b)

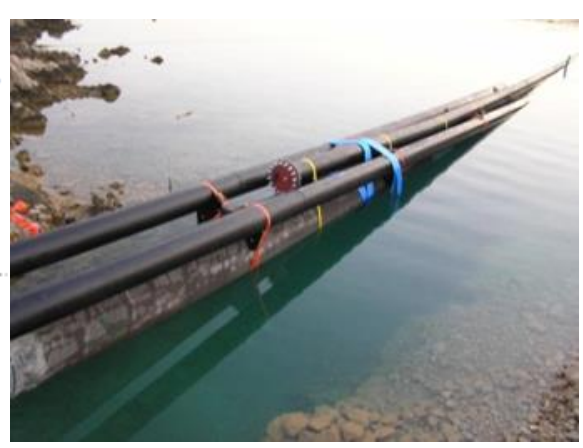

c)

Fig. 5 Subsea pipe with buoyant elements: a)- Primary and secondary buoyant elements in towing, b)- Primary buoyant elements in lowering, c) -Launching the pipe string

\subsection{Surface towing from the platform to the site}

Two tugboats were deployed in towing the pipeline segment from the assembling platform to the site: one leading and one trailing. Two tugs were necessary not only for maneuvering but also to keep the pipeline in tension while it is towed on the surface. During the towing the pipeline segment is vulnerable to damage from waves, requiring a calm weather window.

The towing resistance force was estimated according to the empirical relation reported in Ref. [8]:

$$
R=\frac{1}{2} \rho v^{2} S\left(1.0+0.54 F n^{2}\right) K_{n} K_{t}+10.6 \rho d_{p}^{2} K_{w}^{2} h_{w}^{2}
$$

where: $S$ - pipe end buoyancy elements immersed section area, $\rho$ - sea density, $v$ - towing speed, $F_{n}$ - Froude number, $h_{w}$ - wave height, $d_{p}$ - buoyancy element diameter, $K_{n}, K_{w}$ measured empirical coefficient. The coefficients are also given in [8] for the similar problem. The Froude number $F_{n}$ is defined as:

$$
F n=\frac{v}{\sqrt{g d_{p}}} \text {. }
$$

The minimum towing speed defined by the manoeuvring criteria was between 5 and 6 knots. The resistance of the pipe with buoyancy elements is presented in Fig. 6.

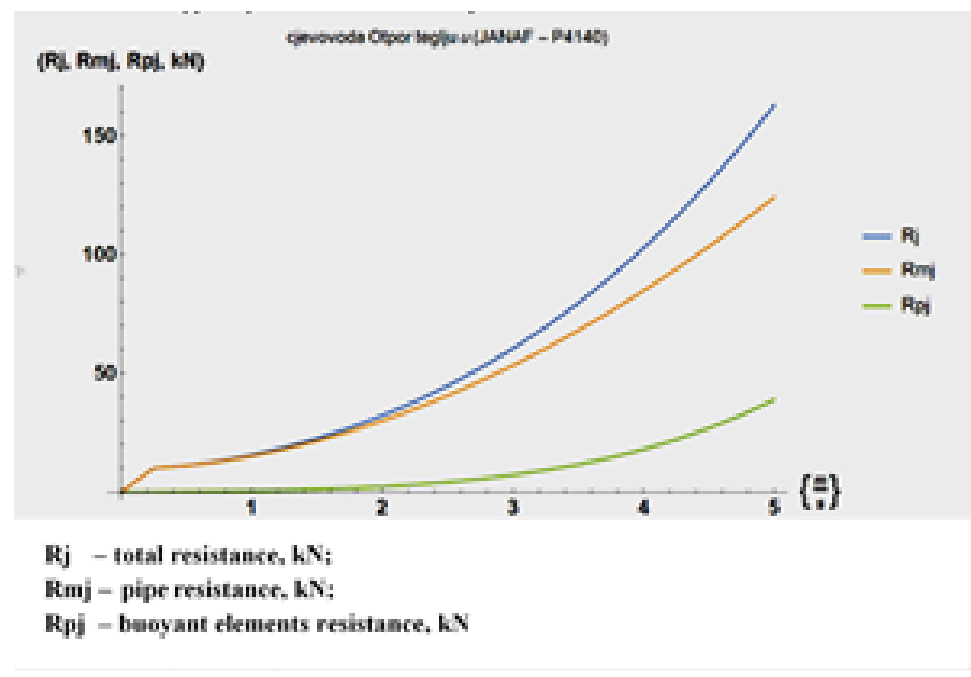

Fig. 6 Resistance of the pipe string in tow 


\subsection{Positioning over the subsea trace}

The total length of the pipeline segment is $6 \%$ longer than the distance between the island and land coasts i.e. the distance between points LP1 and LP2. To place the pipeline segment above the subsea pipeline trace line a control of its bending in horizontal and vertical plane was necessary. It was achieved by means of two towing tugs and with the assistance of the pontoon cranes anchored beside the lowering points LP1, LP2 as it is shown in Fig. 7.

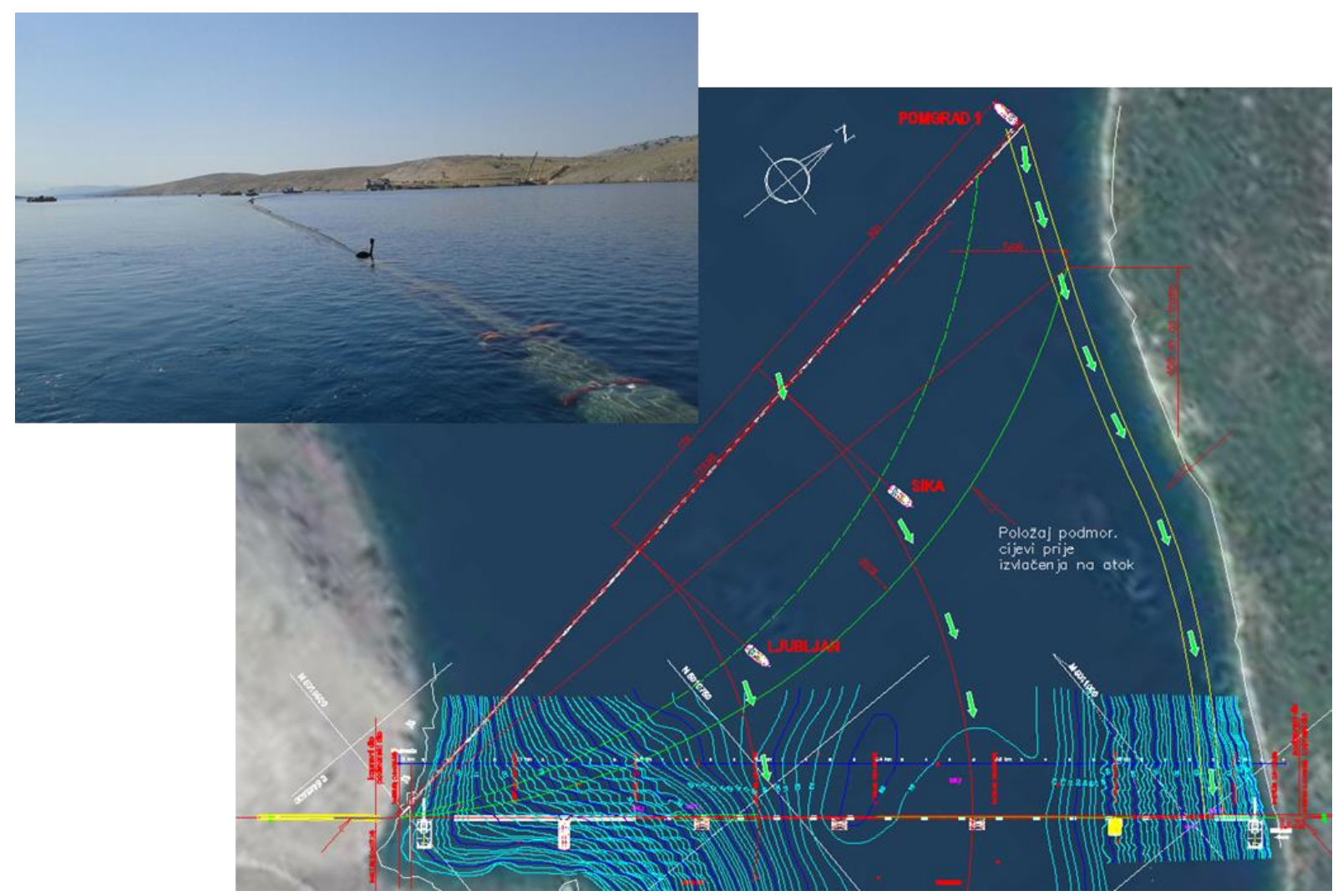

Fig. 7 Positioning of the pipeline between LP1 and LP2 (bending in horizontal plane)

First, a part of the pipeline segment was placed on the island side which is less steep than the land side. This part was laid on the slipway prepared for that purpose, see Fig. 8, whilst the rest of the pipeline segment was hanged on two pontoon cranes near the coasts and five equally distanced pontoons P1 to P5, Fig. 9. From this position pipeline segment laying to the sea bottom started.

\subsection{Controlled lowering on the sea bottom}

The natural sea bottom on the chosen pipeline trace line was curved and bumpy. The necessary subsea construction works were performed to improve the pipeline trace line before the pipeline segment laying. In order to reduce the high expenses of underwater works, the compromise was made between the necessary increase of the pipe section dimensions (pipe thickness), which would prevent excessive bending of the pipeline segment on the curved sea bottom, and the amount of the sea bottom reconstruction works (levelling and smoothing) required for obtaining acceptable curvature $R_{\text {elst }}$. The minimum radius of bottom curvature was estimated according to the linear beam bending theory for the composite pipe section:

$$
R_{\text {elst }}=\frac{E I}{M_{a}}=S_{F} \frac{E I}{\sigma_{y} W}=\frac{1}{2} S_{F} D\left(1+2 \frac{a}{D}\right) \frac{E}{\sigma_{y}} \approx 600 \quad \mathrm{~m}
$$


In above relation $I, W, E, \sigma_{y}$ are pipe composite section moment of inertia, sectional modulus, modulus of elasticity and material yield stress, respectively. Only the concrete material in compressed area of the pipe coat section is supposed to be active and therefore the bending of the section is unsymmetrical. The displacement of the section neutral axis from the geometric axis of symmetry is given by a. Allowable bending radius $R_{\text {elst }}$ was calculated with relatively high safety factor $\mathrm{SF}=2(50 \%$ pipe structural capacity) which defined high safety margin in the pipeline segment laying process related to the bending problem.
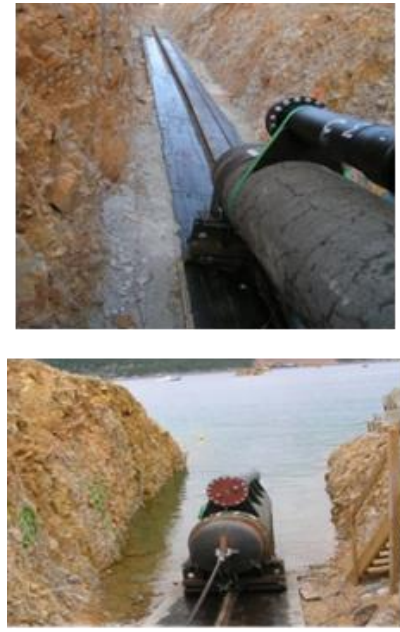

a)

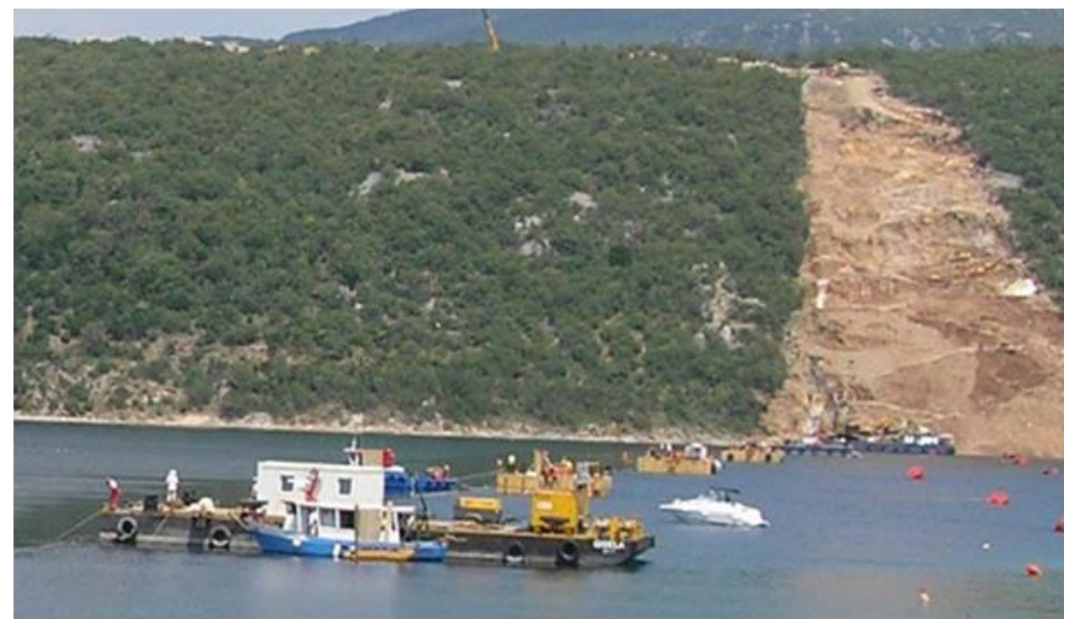

b)

Fig. 8 Positioning the pipeline on the island side, over the trace line plane: a) The pipe hanged on the slipway in the island side, b) Pipeline controlled by the pontoons

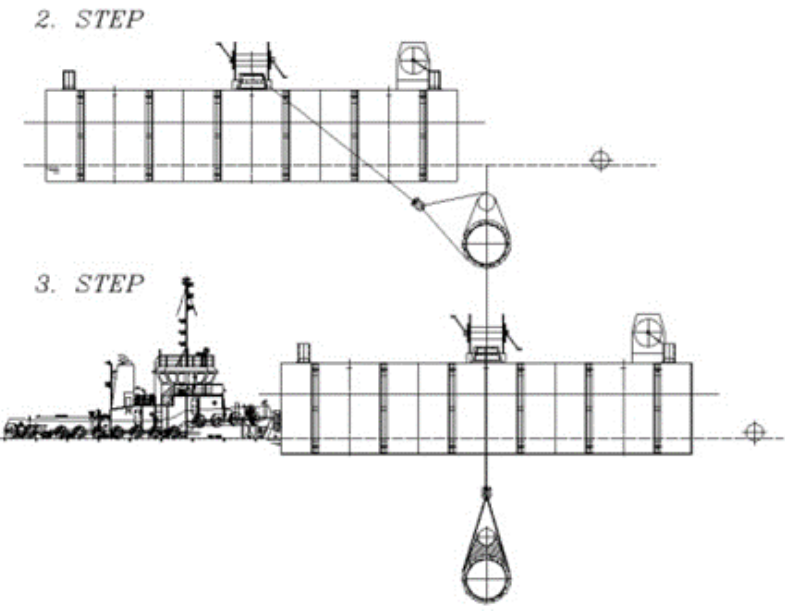

a)

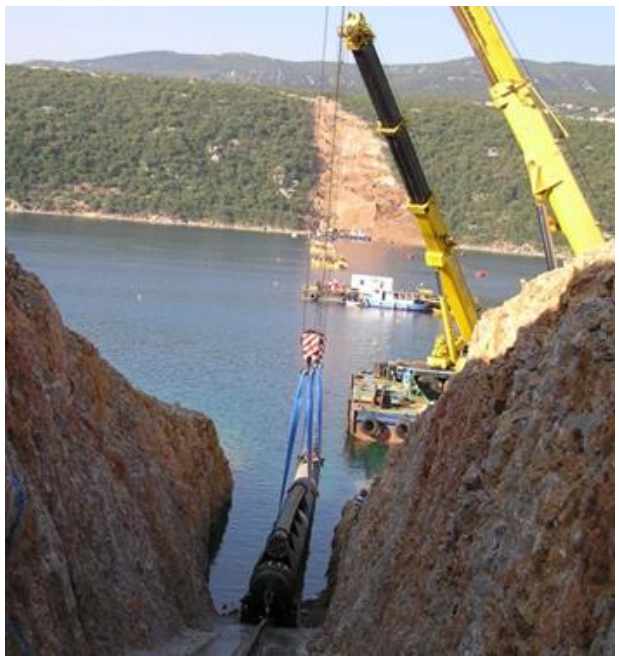

b)

Fig. 9 Positioning the pipeline over the subsea pipeline trace line: a) The pipe section hanged on the pontoon, b) The start pipe section controlled by the pontoon crane

Beside the excessive bending problem, the most critical situation in laying process is eventual excessive pipeline segment uplifting with possible local buckling on the sea bottom, Fig. 10. It may happen if the unsupported parts of the pipe touch the sea bottom before the suspending points sections. The bottom friction prevents in that case free longitudinal relaxation of the pipe on the bottom. 
Very precise synchronization of the vertical displacements of the suspending points from the supporting pontoons was necessary to avoid the pipe uplift and excessive bending moment during the pipeline laying, see Fig. 11.

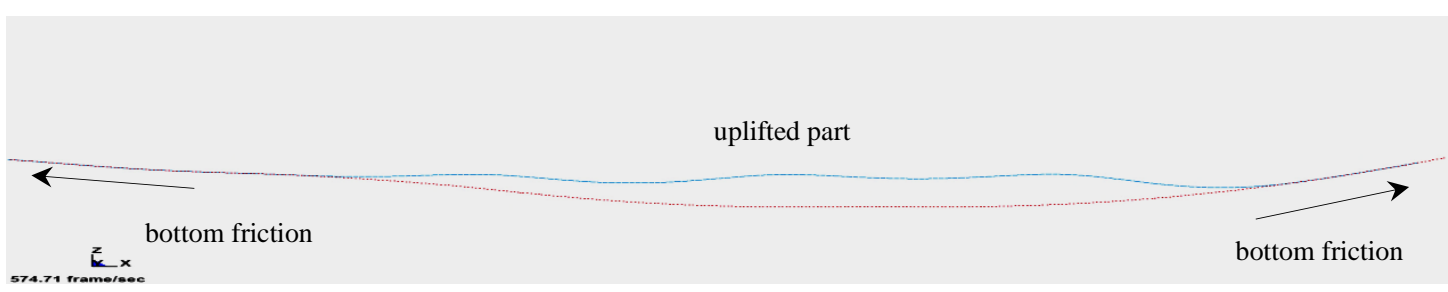

Fig. 10 Pipeline on the sea bottom in upheaval buckling (FEM simulation)

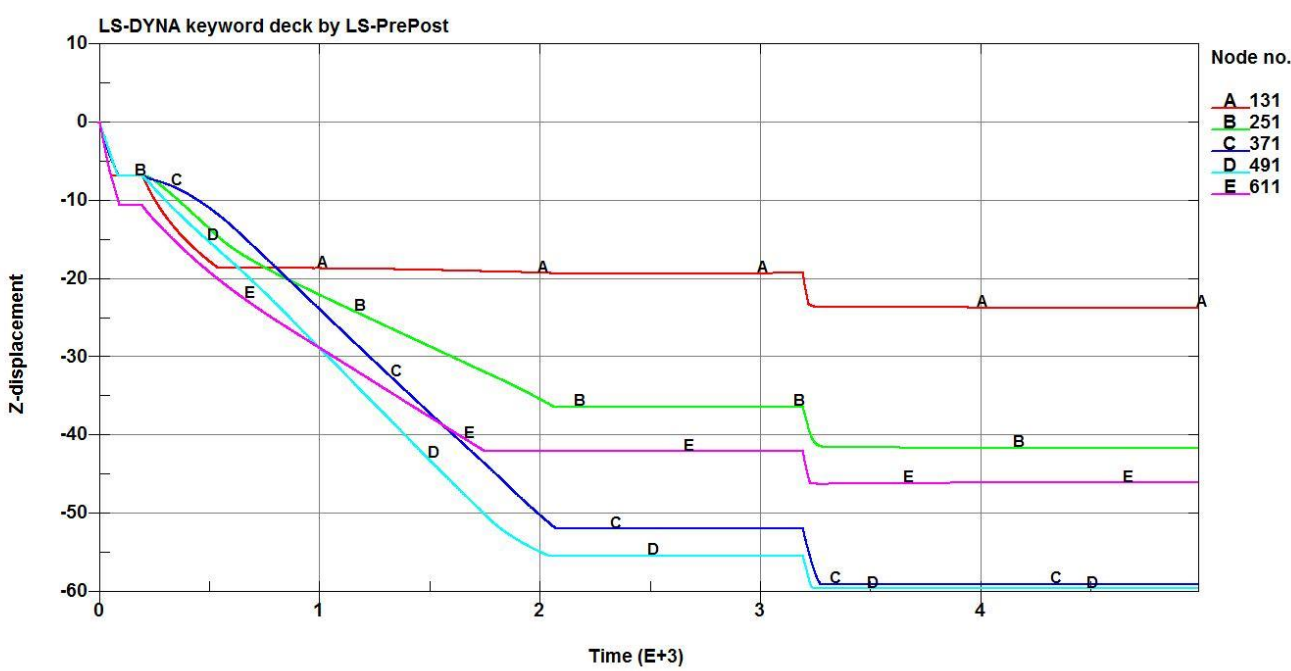

a) Vertical displacement

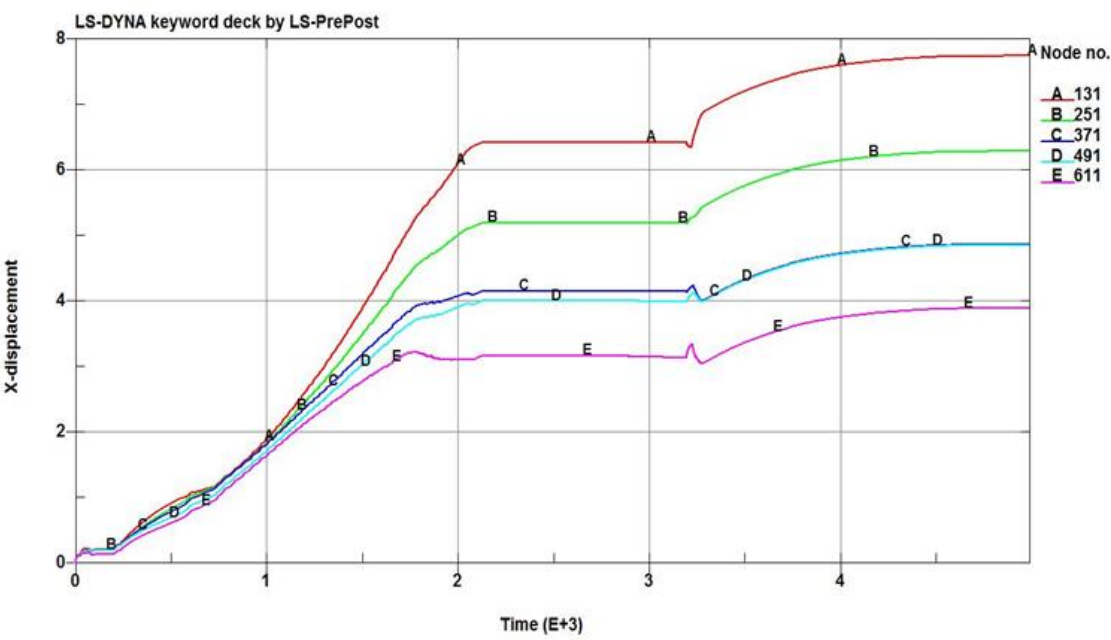

b) Horizontal displacement

Fig. 11 Time synchronization of pipeline suspending points displacements

The laying process was divided into two parts. In the first part the pipeline segment was laid from the sea surface to the position just above the sea bottom $(1.0-1.5 \mathrm{~m}$ over the sea bottom), see Fig. 15. At this moment, the pipeline segment has not yet touched the bottom and it is supported in floating by its own buoyancy and the buoyancy of the primary buoyancy 
elements, reaction on the island slipway, two pontoon cranes near the island and in-land coastline and five pontoons. Then, while still in the just-above-the-sea-bottom position, primary buoyancy elements were flooded to increase the weight of the pipe in order to stabilize the pipe with respect to horizontal loading due to sea current. The final phase of laying was performed with precise synchronization of the crane and pontoon activities according to the displacement and bending moment diagrams calculated in numeric simulation.

\subsection{Detailing the function plan}

To supply the project knowledge base with the necessary information about all the critical actions during the installation process, almost all actions were rationally modelled, simulated and analyzed as a part of technology design development process. The models were mainly based on empirical and semi empirical relations from [2], [3] and [4].

For the most critical actions which were positioning of the pipe over the subsea pipe line route and lowering the pipe from sea level to the sea bottom, reliable and very detailed numerically simulations were performed by the finite element method (FEM).

The same FEM model was earlier applied in the optimization procedure of the subsea pipeline main design. It was modified and applied within the present analysis for to take into consideration two following important criteria in pipeline laying analysis:

- uplift displacement if the pipe ends touch the sea bottom before the middle part,

- excessive bending moment between the pipe suspending points.

Several variations of the pipeline laying steps way were examined and compared based on the simulation results before the final version of the laying function plan was defined. The results of numerical simulations, in particular the geometry of the deformed pipe at any position from the sea surface to the sea bottom, enabled the definition of the safe laying process in detail. The results included also the pipe sections loading (bending moments, shear and longitudinal forces) necessary for checking the process with respect to the choice of the equipment, number of necessary pontoons and pontoon cranes.

Applying these results, the top functional plan of the pipe installation process Fig. 3 was detailed in 348 activities from the top to the bottom level. The example of the part of final functional plan on the detailed level is shown in Fig. 12.

\section{Numerical simulation}

The most contemporary software packages for FEM nonlinear structural analysis (LSDyna, ANSYS, Abaqus, NASTRAN, ...) are able to model the present problem in a realistic way by numerical simulation. Details of the model are given in Ref. [1] while theoretical background is clearly explained in Refs.[5,6]. In the basic sense, the problem of the subsea pipeline laying may be described as motion of an elastic body collides to the rigid body - sea bottom. The collision happens at low speed and with small acceleration. During the laying process the pipeline elastic body experiences large displacement of some sections. The pipe structure deformation consists in that case of rigid body displacement and small elastic deformation (combination of classic catenary and beam bending). 


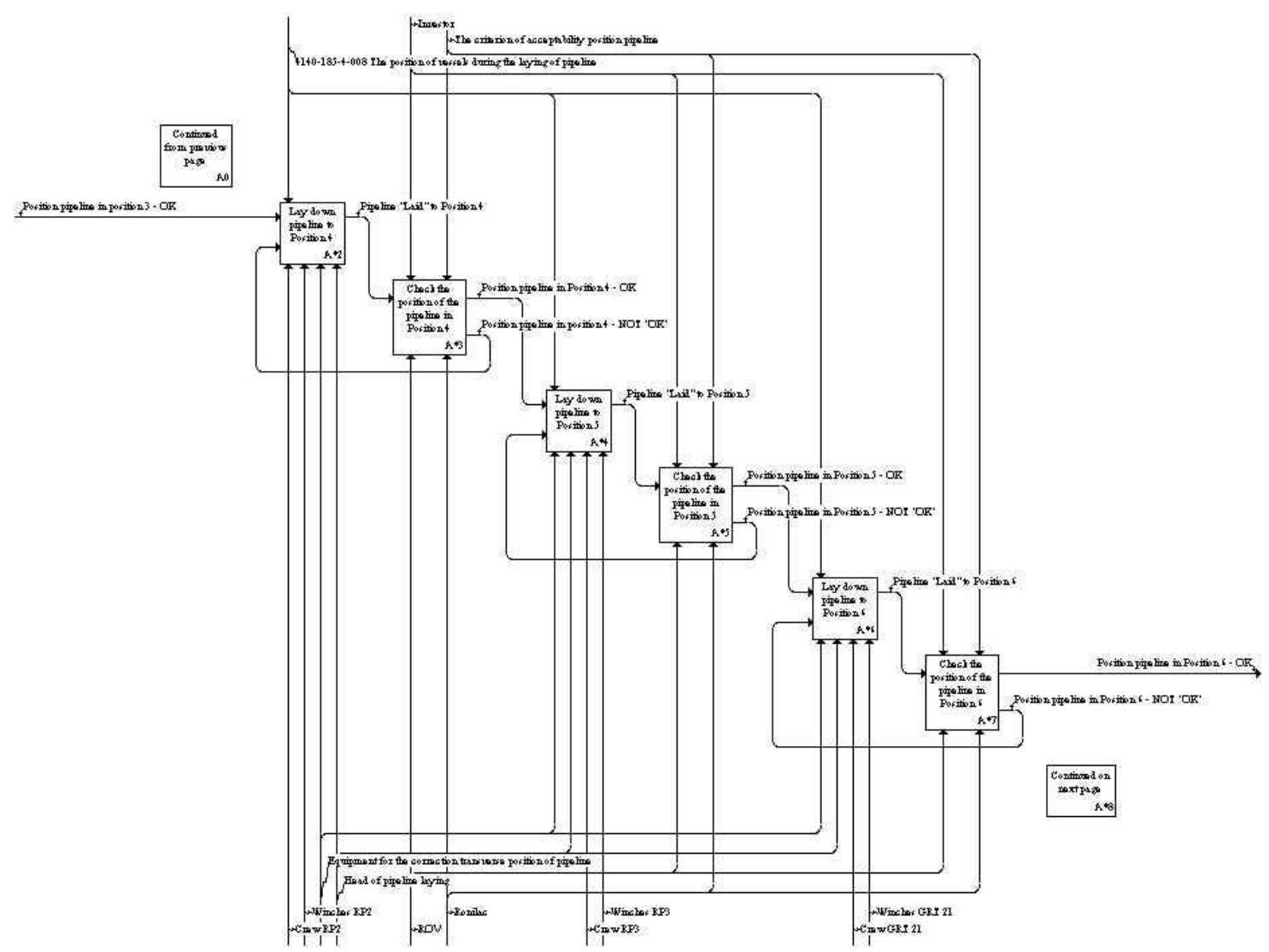

Fig. 12 Functional plan of the pipe laying process, detailed level: pipe positioning

The following nonlinear problems are present in the model:

- the pipe sections experience large displacements but small strain,

- the boundary conditions between the pipe and the sea bottom are undefined because of the contact and sliding along them,

- effective pipe weight during laying is variable.

\subsection{Structural FEM model of the subsea pipeline}

The equilibrium position of the pipeline segment during laying was calculated in the nonlinear dynamic FEM model. The pipe structure was modelled by beam finite elements and the sea bottom by stiff shell elements, Fig. 13. The shell elements nodes were fixed to idealize the rigid sea bottom and coast. The instantaneous beam element nodal displacements were obtained by dynamic equilibrium between body inertial forces, variable buoyancy force and contact reactions. The pipeline body equilibrium at any time $t$ is given in that case by the following momentum equation which sounds in the most general (d'Alambert) form:

$$
f_{I}(t)+f_{D}\left(x_{i}, \dot{x}_{i} ; t\right)+f_{S}\left(x_{i} ; t\right)=m \ddot{u}+c \dot{u}+f_{\text {int }}(u)=p(t)
$$

where $f_{I}, f_{D}, f_{S}$ are inertia, dumping and restoring (internal) force, are position, velocity and acceleration vector, respectively. For nonlinear problems the equations of motions are integrated by explicate central difference scheme taking into account the variable boundary conditions if the contact problem is present. 


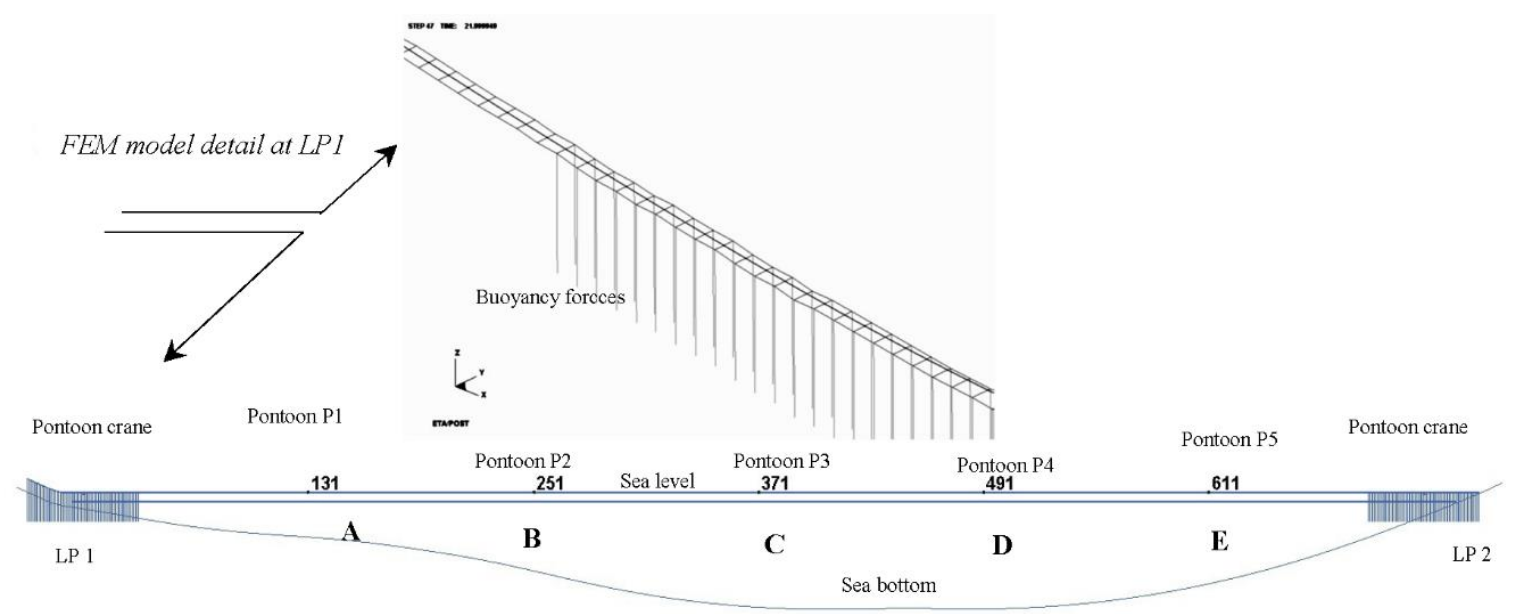

Fig. 13 Subsea pipeline FEM model: beam elements - (coated pipe NP 36")

The maximum deflection of the pipeline at the deepest part of the trace line is larger than 50 pipe diameters which is a phenomenon much beyond the limits of classical beam bending theory. Appropriate type of the beam finite element had to be applied to solve the problem of large displacement/small deformation with sufficient accuracy (in time domain). A special beam finite element, so called Belytschko beam was chosen for this purpose. The formulation of this finite element in co-rotational technique separates the deformation displacements from the rigid body displacements which do not affects strains and associated strain energy, [5].

Nonlinear finite element technique applies adjusted iterative algorithms which recognize the contact problem. The present problems were successfully solved with master/slave nodes technique, see [1] and [5], [6] for details.

The following load system acts on the pipeline segment during the laying:

- gravity load (given),

- reaction forces on the pontoons and pontoon cranes (calculated),

- variable distributed reaction on the part which is in contact with ground and sea bottom (calculated),

- variable buoyancy which depends on the part immersed in sea and is a function of the instantaneous nodal displacement (calculated).

The beam elements in the model were loaded by effective weight which is the difference between the gravity load and the total buoyancy of immersed part. The overall load depends then on the pipeline part which is partly immersed or it is in air and is taken into account directly by applying the forces whose intensity depends on the position of the beam element nodes with respect to the sea level, see Fig. 13.

\subsection{Results of simulation}

The feasibility of the project function plan in all details was proved on the basis of the simulation results. Two groups of result data were essential:

- the geometry of the bended subsea pipe,

- pertaining bending moment diagrams. 
The illustrative examples of the essential parameters - pipeline segment bending moment and bended pipeline segment geometry, with respect to the sea bottom, are shown in diagram form in, see Fig. 14 and Fig. 15.

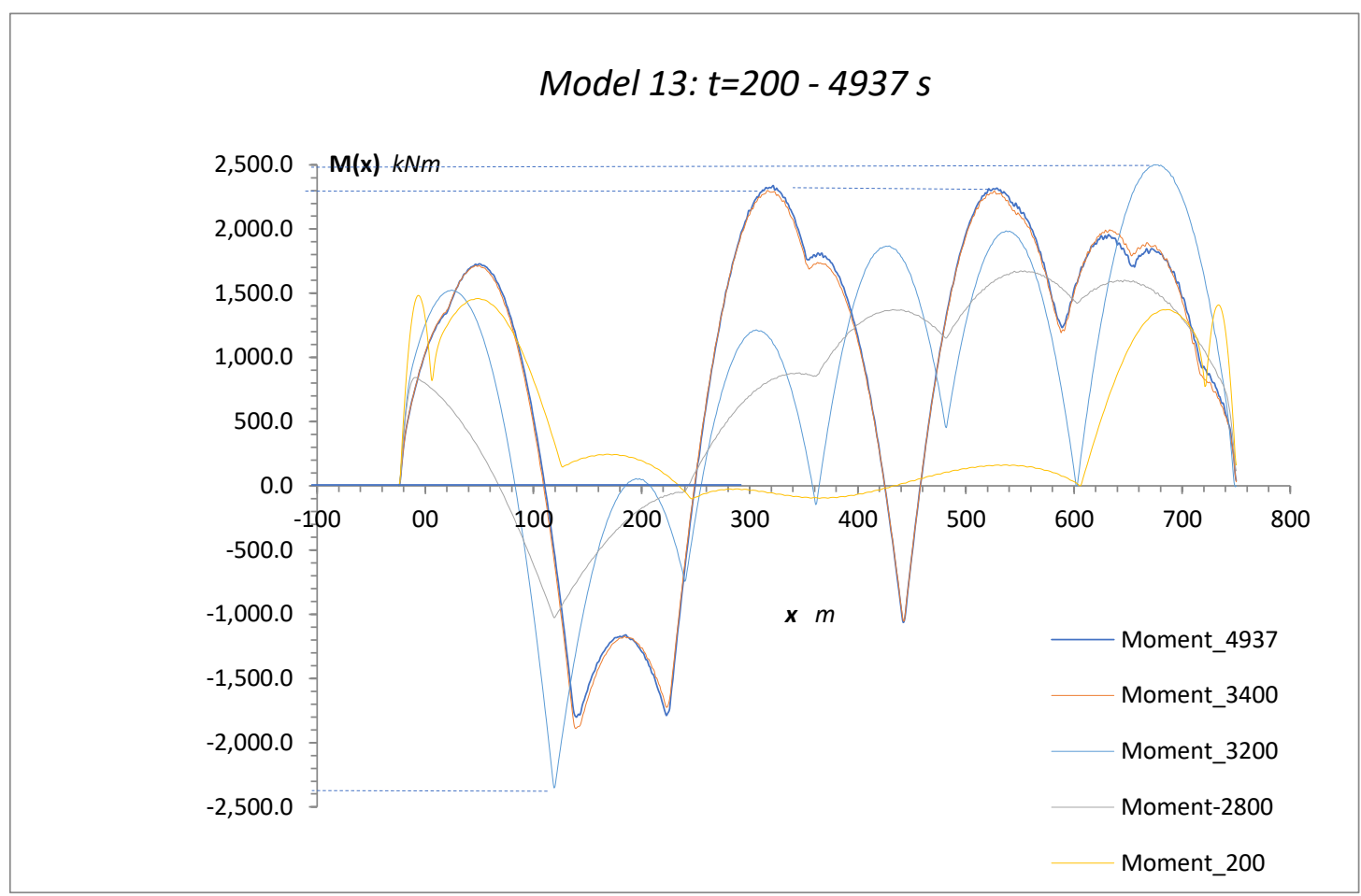

Fig. 14 Pipe bending moment during laying phases (numerical simulation in time $t=200,2800, \ldots, 4937 \mathrm{~s}$ )

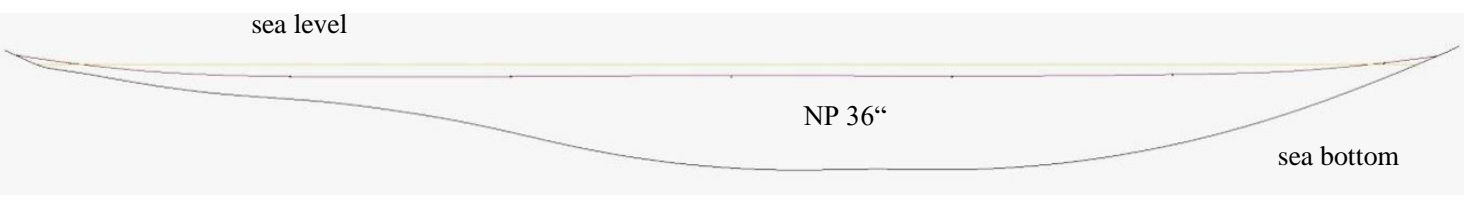

a) Pipe in the initial position (pipe with primary buoyancy elements, hanged on pontoons and supported by slipway; simulation time $t=200 s$ )

sea level

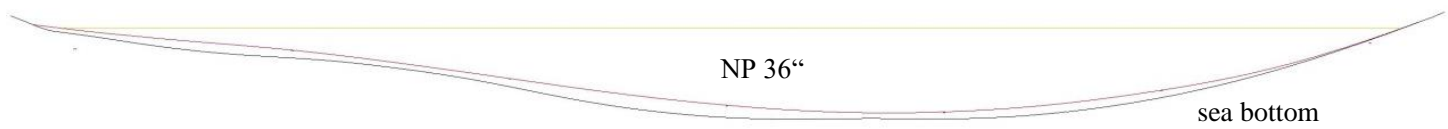

b) Pipe position just above the sea bottom (pipe with primary buoyancy elements, hanged on pontoons P1 to P5 and supported by slipway; simuation time $t=2800 \mathrm{~s}$ )

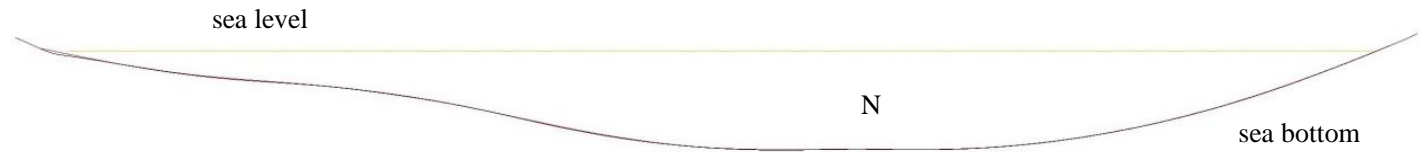

c) Position on the sea bottom (simulation time $t=3400 \mathrm{~s}$, touch moment)

Fig. 15 Geometry of the bended subsea pipeline in different laying phases 


\section{Conclusion}

An excessive engineering was made to define reliable technology and organization of the subsea pipeline segment laying in difficult condition, between steep island and land coasts and over the curved and bumpy sea bottom.

Very detailed engineering of the laying process was performed on the basis of nonlinear structural FEM analysis and detailed function plan. The pipeline segment was successfully laid according to the function plan in available time window without any accident.

The present engineering was made in cooperation between the company Pomgrad, who carried out the underwater construction work on the pipeline trace and who was responsible for installation of the pipeline and a design office Armania which produced detailed function plan and technical description of the procedure.

The numerical simulations of the installation process were calculated at the Department of Naval Architecture and Ocean Engineering at Faculty of Mechanical Engineering and Naval Architecture University of Zagreb. The subsea pipeline and its installation was realized under the approval and inspection of Croatian Register of Ships (CRS).

\section{Acknowledgements}

The authors express their thanks to the ARMANIA ltd. Company which enabled them access to the data presented in this paper.

\section{REFERENCES}

[1] Čorić, V, Ćatipović, I., Radanović, J.: Subsea Pipe Laying in Coastal Area. Proceeding of 20th symposium Theory and Praxis in Shipbuilding - SORTA 2012, p.p 235-248

[2] Offshore Standard Det norske Veritas DnV-OS-F101: Submarine Pipeline Systems; October 2007 (C) Det norske Veritas

[3] DNV RP F109 - On-bottom Stability Design of Submarine Pipelines; Det norskeVeritas; 2010

[4] Code practice for Maritime structures: Part 6 - Design of inshore moorings and floating structures; BS $6349-6 / 1989$

[5] Hallquist, J.O: LS-Dyna Theory Manual; Livermore Software Technology Corporation, Livermore, 2006

[6] ANSYS - Theory Reference for the Mechanical APDL and Mechanical Applications; ANSYS, Inc. Southpointe; 2009

[7] Mayer, R. J.; Paula S. deWitte: Delivering Results: Evolving BPR from Art to Engineering; Business Process Reengineering; Kluwer

[8] Kamyshev, M.A.; Kamysev, A.M.; Shabo, N.V.; Sokolovsky, G.N.: Hydrodynamic Drag of Pipeline in Broken Ice; Proc. of 11th IOPE; Stavanger; 2001

$\begin{array}{lll}\text { Submitted: } & \text { 16.03.2017. } & \begin{array}{l}\text { Većeslav Čorić, veceslav.coric@ @fsb.hr } \\ \text { Smiljko Rudan, } \underline{\text { smiljko.rudan@ fsb.hr }}\end{array} \\ \text { Accepted: } & \text { dd.mm.yyyy. } & \text { Faculty of Mechanical Engineering and Naval Architecture University of } \\ & & \text { Zagreb, 10000 Zagreb, Ivana Lučića 5 } \\ & & \text { Slobodan Maksimović, armanija@armanija.hr } \\ & & \text { Aramanija d.o.o., 21000 Split, Ruđera Boškovića 5 }\end{array}$

